\title{
Encapsulation of Non-Hydrogen Atoms by in,in-Bis(triarylelement)-Containing Cyclophanes
}

Jie Zong, Joel T. Mague, and Robert A. Pascal, Jr.*

Department of Chemistry, Tulane University, New Orleans, LA 70118, USA

Keywords: cyclophanes, in/out isomerism, non-bonded interactions, through-space coupling *Corresponding author. Tel.: +1-504-862-3547; fax: +1-504-865-5596; e-mail:

rpascal@tulane.edu

\begin{abstract}
Four unusual in,in-cyclophanes have been synthesized-the macrobicyclic in, in-bisphosphine 11, its $\operatorname{Ag}(\mathrm{I})$ complex 12, the in-hydroxysilane-in-phosphine 16, and an inseparable mixture of $\mathbf{1 6}$ with the in-fluorosilane-in-phosphine 17-and the in, in geometries have been confirmed by X-ray crystallography. In complex 12, the silver atom is encapsulated in a hydrophobic cavity, and it experiences strong spin-spin coupling to the phosphorus atoms. In the cyclophanes $\mathbf{1 6}$ and $\mathbf{1 7}$ an inwardly directed hydroxyl group or fluorine atom is pressed against the lone pair of the opposing, inwardly directed phosphine.
\end{abstract}




\section{Introduction}

We recently reported the synthesis and crystallographic characterization of macrobicycles 1-5, each of which contains two inwardly pyramidalized bridgehead atoms. ${ }^{1-4}$ In every case, the bridgeheads bear either lone pair electrons or hydrogen atoms. All attempts to introduce larger atoms into the interior spaces of these or similar structures, whether by cyclization with larger bridgehead substituents ${ }^{3}$ or reactions of the bridgehead atoms (e.g., oxygenation), ${ }^{1,3}$ have been unsuccessful, and even the protonation of the in-phosphines in compounds $\mathbf{1}$ and $\mathbf{3}$ is slow due to the severe steric congestion in these cyclophanes. ${ }^{1,3}$ Indeed, in Alder and East's 1996 review of in/out isomerism, ${ }^{5}$ there is not a single example of an in,in-macrobicycle that contains an inwardly-directed non-hydrogen atom attached to the bridgehead (i.e., 6). A later review by Bauer and Habicher ${ }^{6}$ gives three examples of in, in-cyclophanes with inwardly directed $\mathrm{P}=\mathrm{O}$ groups, but in these molecules the phosphorus atoms are separated by three chains of 15 or 16 atoms $;{ }^{7,8}$ thus there is little, if any, steric conflict. A search of the most recent version of the Cambridge Structural Database ${ }^{9}$ (CSD) for similar structures found no additional examples.
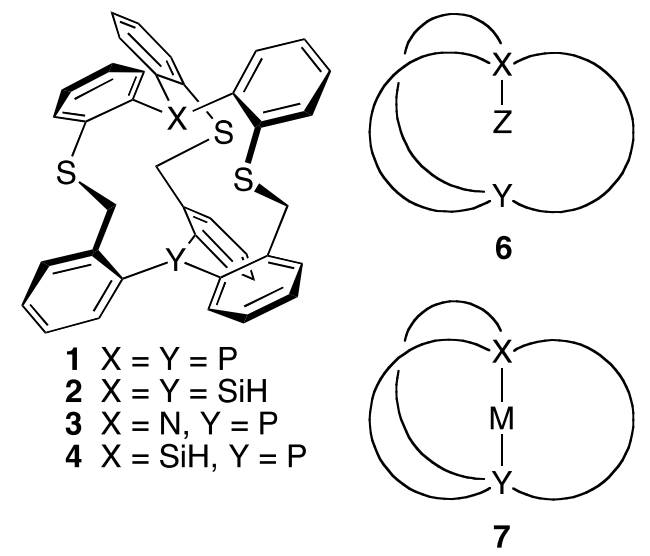

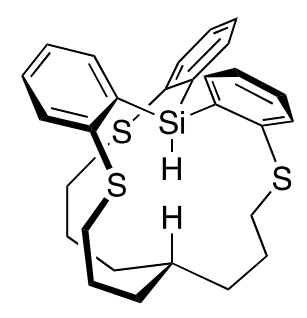

5

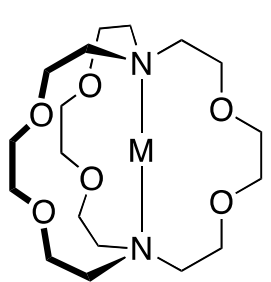

8 
Molecules resembling structure $\mathbf{6}$ are exceptionally rare, but the encapsulation of metal ions by in, in-macrobicycles (7) is far more common. For example, the CSD contains more than 700 examples of the structure $\mathbf{8}$, where $\mathrm{M}$ is an alkali or alkaline earth metal ion! However, transition metal complexes of this type are only infrequently reported. An extensive search of the CSD found only eight examples of transition metal complexes using [2.2.2]cryptand (i.e., 8), as well as another eight transition metal complexes that use different cryptands or cryptand-like ligands. All such compounds featured nitrogen atoms at the bridgeheads of the macrobicycles. Only a single complex was found that contained phosphorus atoms at the bridgeheads: a macrobicyclic bis(phosphite) complex of square-planar platinum with cis stereochemistry (the P-Pt-P angle is $\left.100.1^{\circ}\right),{ }^{10}$ bearing little resemblance to $C_{3}$ or $D_{3}$ symmetric structures such as $\mathbf{8}$.

In this paper we report several unusual "encapsulations" by macrobicycles. First, we describe the preparation of the bisphosphine 11 and its silver complex 12 (Scheme 1), and second, we describe the synthesis of the in,in-macrocycles $\mathbf{1 6}$ and $\mathbf{1 7}$, the former as the pure in-hydroxy compound and the latter as an inseparable mixture of in-hydroxy- and in-fluorosilanes, both of whose interior atoms must interact with the phosphorus atom on the opposing bridgehead.

\section{Results and Discussion}

\subsection{Synthesis and Structure of Silver Complex 12.}

The synthesis of the bis(phosphine) $\mathbf{1 1}$ and its silver complex $\mathbf{1 2}$ is illustrated in Scheme 1. Treatment of tris[2-(chloromethyl)phenyl]phosphine ${ }^{11}$ (9) with thiourea, followed by base hydrolysis, gave the corresponding trithiol $\mathbf{1 0}$ in excellent yield (96\%). A solution of $\mathbf{9}$ and 10, each at a concentration of $1 \mathrm{mM}$ in 2:1 benzene-EtOH at reflux, was then treated with $\mathrm{KOH}$ to give the in, in-bis(phosphine) $\mathbf{1 1}$ in $22 \%$ yield, a fairly good yield for such a macrocyclization. 


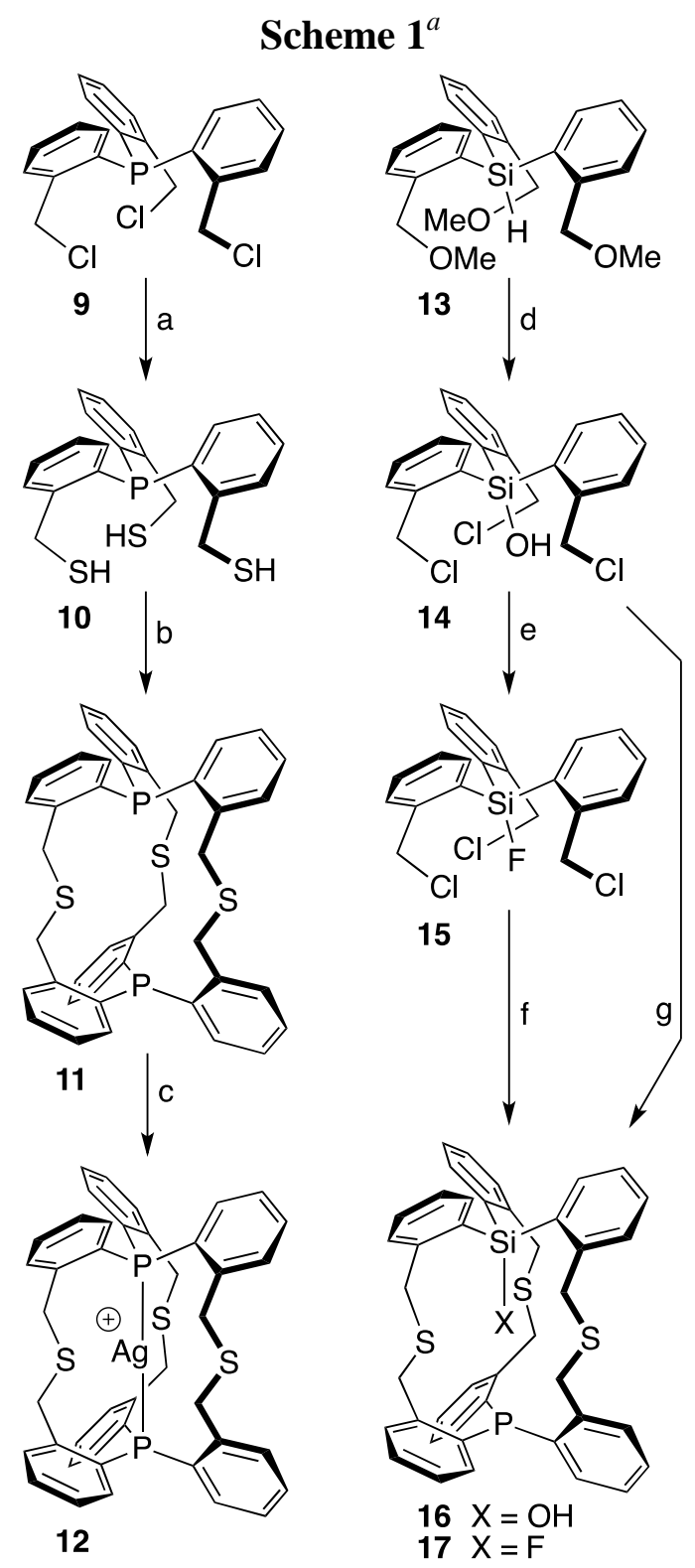

${ }^{a}$ Conditions: (a) thiourea, EtOH, reflux; then $\mathrm{KOH}, \mathrm{H}_{2} \mathrm{O}$, reflux; then $\mathrm{HCl}, 96 \%$ (b) 9, $\mathrm{KOH}, 2: 1$ benzene-EtOH, reflux, 22\%; (c) $\mathrm{Ag}(\mathrm{OAc}), \mathrm{CHCl}_{3}, \sim 80 \%$; (d) $\mathrm{BCl}_{3}$, heptane, then $\mathrm{H}_{2} \mathrm{O}, 32 \%$; (e) $\mathrm{BF}_{3} \cdot \mathrm{Et}_{2} \mathrm{O}, \mathrm{CH}_{2} \mathrm{Cl}_{2}, 55 \%$; (f) $\mathbf{1 0}$, $\mathrm{KOH}, 2: 1$ benzene-EtOH, reflux, $1 \%$ of $\mathbf{1 6 / 1 7}$ mixture; (g) 10, KOH, 2:1 benzene-EtOH, reflux, $14 \%$ of $\mathbf{1 6}$.

Compound $\mathbf{1 1}$ is considerably less soluble than the other in,in-cyclophanes that we have prepared, ${ }^{1-4}$ but due to its high symmetry $\left(C_{3 h}\right)$, good NMR spectra were easily obtained. Its ${ }^{1} \mathrm{H}$ NMR spectrum displays highly broadened, diastereotopic methylene resonances due to the slow flipping of the triarylphosphine caps on the NMR time scale. The ${ }^{13} \mathrm{C}$ NMR spectrum shows the 
expected seven resonances, but three of these are complex multiplets due to coupling with the phosphorus atoms. Single crystals of $\mathbf{1 1}$ were obtained from acetone- $\mathrm{CH}_{2} \mathrm{Cl}_{2}$, and its X-ray structure is illustrated in Figure 1.

When compound 11 was stirred with silver acetate in $\mathrm{CDCl}_{3}$ overnight, the $\mathrm{NMR}$ spectra of the resulting solution (some residual solid was filtered away) indicated nearly complete conversion to the silver complex 12. Most significant is the ${ }^{31} \mathrm{P}$ NMR spectrum of the complex, in which very strong silver-phosphorus coupling is observed $\left[J_{\mathrm{AgP}}=482 \mathrm{~Hz}\left({ }^{107} \mathrm{Ag}\right), 556 \mathrm{~Hz}\left({ }^{109} \mathrm{Ag}\right)\right]$. The MALDI-TOF mass spectrum shows a clean molecular ion for the cationic portion of the silver complex (the acetate counterion is not observed). Many unsuccessful attempts were made to crystallize complex 12, but, at last, concentration of a solution in $\mathrm{MTBE}_{-\mathrm{CDCl}}$ gave satisfactory crystals. The structure of the complex is also illustrated in Figure 1.

Figure 1. Molecular structures of bis(phosphine) 11 (left) and its silver(I) complex 12 (right). Thermal ellipsoids are drawn at the $50 \%$ probability level.
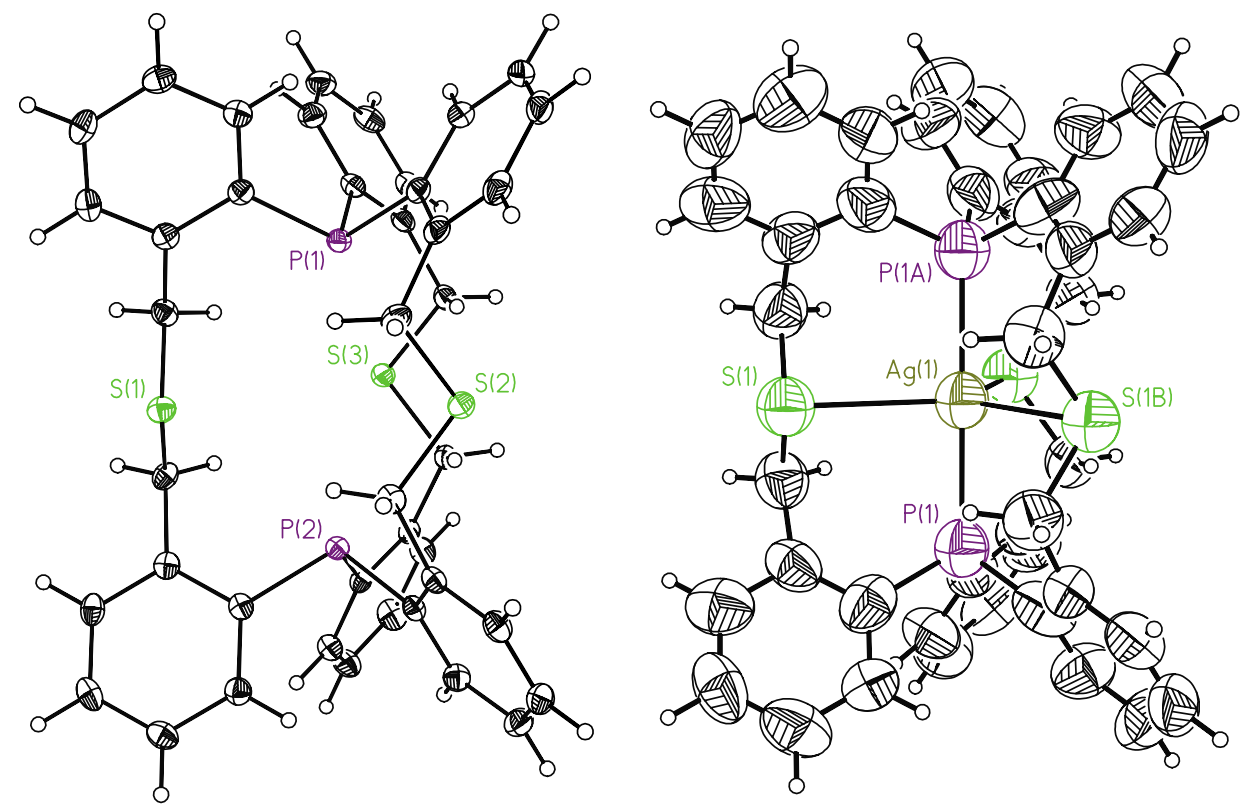
Although compounds $\mathbf{1 1}$ and $\mathbf{1 2}$ are very similar in shape, from a crystallographic perspective they could hardly be more different. Bis(phosphine) $\mathbf{1 1}$ crystallized on a general position in the common monoclinic space group $P 2_{1} / n$ (No. 14). The molecule adopts a conformation of approximate $C_{3 h}$ symmetry, and the structure refined without problems to an excellent conventional $R(F)=0.027$. In contrast, complex 12 crystallized on a special position in the hexagonal space group $P 6 / m$ (No. 175). In this case, the cationic complex possesses crystallographic $C_{3 h}$ symmetry and is well ordered, but the attendant acetate ion and included solvent is highly disordered and compromises the quality of the overall structure. The anion and solvent density was removed by the SQUEEZE/BYPASS procedure, ${ }^{12}$ and the structure refined to an acceptable $R(F)=0.097$.

Only slight distortions are required for the ligand $\mathbf{1 1}$ to accommodate the silver ion in complex $\mathbf{1 2}$. In the free ligand, the phosphorus-phosphorus distance is $4.99 \AA$; in the complex this is reduced slightly to $4.92 \AA$, and thus the Ag-P bond distances are $2.46 \AA$ each. The sulfur atoms in the bridging thioether chains appear to have only minimal interactions with the silver ion, even though the X-ray software draws three Ag-S “bonds" (see Figure 1). The silver-sulfur distances are 2.92 $\AA, 0.46 \AA$ longer than the Ag-P bonds, and somewhat greater than the sum of the ionic radius of $\operatorname{Ag}^{+}\left(0.81 \AA^{13}\right)$ and the van der Waals radius of $S\left(1.80 \AA^{14}\right)$. Thus complex 12 is best regarded, electronically at least, as a conventional, linear, divalent $\operatorname{Ag}(\mathrm{I})$ complex. However, it must be noted that the flipping of the side chains, a process evident in the ${ }^{1} \mathrm{H}$ NMR spectrum of 11, is not observed in spectra of the silver complex 12, and may reflect a degree of coordination of the silver ion by the sulfur atoms.

\subsection{Synthesis and Structure of in,in-Cyclophanes 16 and 17.}

Treatment of tris[2-(methoxymethyl)phenyl] silane ${ }^{15}$ (13) with $\mathrm{BCl}_{3}$ gave tris[2-(chloromethyl)phenyl]silanol (14) in $32 \%$ yield. In fact, we have used exactly the same procedure to prepare 
Thus it seems that compound $\mathbf{1 6}$ is formed significantly more easily than $\mathbf{1 7}$, even though the in-fluorine of the latter macrocycle is sterically less demanding. We speculate that hydrogen bonding between the hydroxyl group and the phosphine and/or the thiolate anion in a partially cyclized macrocycle (e.g., 18) may facilitate the final ring closure, but the interaction of a fluorine atom with the lone pair electrons of a phosphine or thiolate at the same stage is purely repulsive. There is no doubt that the phosphine and hydroxyl group interact in compound 16: in its ${ }^{1} \mathrm{H}$ NMR spectrum, the hydroxyl proton is visible as a doublet $\left(J_{\mathrm{PH}}=4 \mathrm{~Hz}\right)$ at $\delta 6.50$.

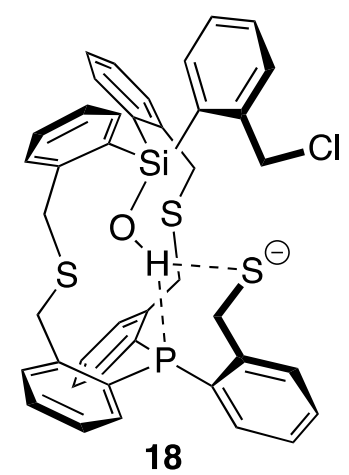

Satisfactory crystals of these compounds were difficult to obtain, but eventually single crystals of the $\mathbf{1 6} / \mathbf{1 7}$ mixture were obtained from $\mathrm{CHCl}_{3}$ solution, and the molecular structure of $\mathbf{1 7}$ is illustrated in Figure 2. This material crystallized in the hexagonal space group $P \overline{6} 2 c$ (No. 190), with two independent molecules in the structure, each located on a special position with crystallographic $C_{3 h}$ symmetry. Unfortunately, since $\mathbf{1 6}$ and $\mathbf{1 7}$ are at most $C_{3}$ symmetric, this means that the resulting structure is disordered end-to-end, with the silicon and phosphorus atoms indistinguishable; furthermore, there is the occupational disorder resulting from the presence of both in-hydroxysilane $\mathbf{1 6}$ and in-fluorosilane 17. However, because the two molecules are so similar in shape, and the two ends of the molecules are so much alike, the disorder is relatively easily modeled, and the structure refined to a very reasonable $R(F)=0.079$. Nevertheless, the bond distances and angles in this structure cannot possibly be as accurate as those from a well-ordered structure. 
Figure 2. Molecular structure of cyclophane mixture 16/17. One of the two independent molecules is illustrated (molecule 2), only one orientation of the disordered structure is illustrated, and the in-atom is illustrated as a fluorine atom, although both fluorine and oxygen are present. Thermal ellipsoids are drawn at the 50\% probability level.

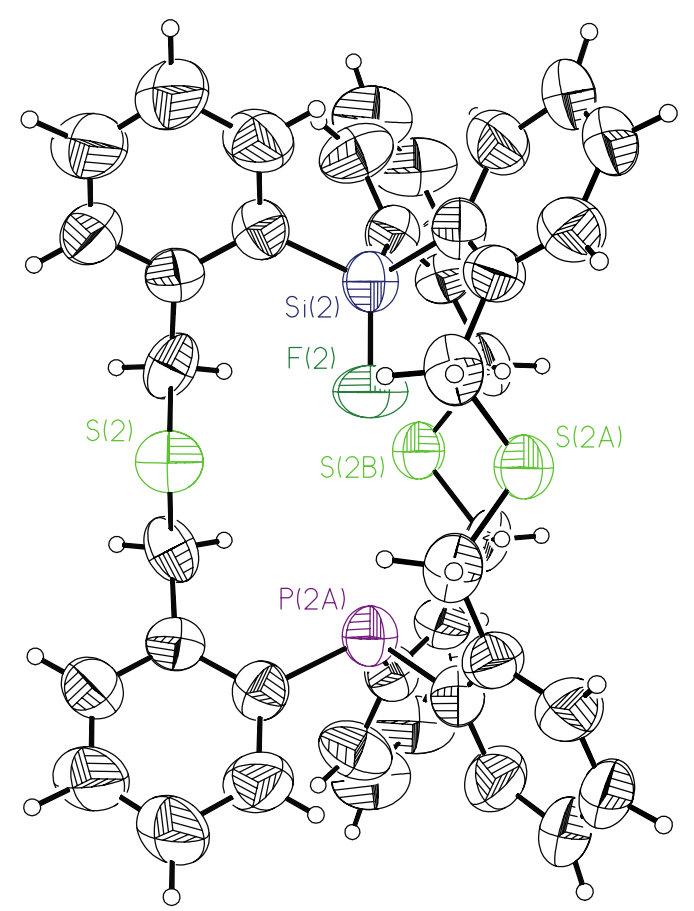

For this reason, we examined the structures of compounds 16 and 17 with HDFT calculations. The structures of $\mathbf{1 6}$ and $\mathbf{1 7}$ were optimized at the B3LYP/6-311++G(2df,2pd) level of theory, and calculations of their NMR spectra, including selected coupling constants, were performed at the same level. (The large basis set is recommended in order to give accurate through-space coupling constants. ${ }^{4,17}$ ) As noted above, the X-ray structure contains two independent molecules of $\mathbf{1 6 / 1 7}$; molecule 1 is somewhat compressed when compared to the HDFT-calculated geometries, but molecule 2 (illustrated in Figure 2) very closely resembles the calculated structures. The salient geometric parameters for the experimental and calculated structures are found in Table 1. When comparing these data it must be born in mind that the Si-OH and Si-F bond distances were fixed at $1.600 \AA$ and $1.645 \AA$ in the X-ray refinement, and that the experimental $\mathrm{Si}^{\cdots}{ }^{\cdots} \mathrm{P}$ distance reflects contributions from both $\mathbf{1 6}$ and $\mathbf{1 7}$. 
Table 1. Experimental and Calculated Atom-Atom Distances for Compounds $\mathbf{1 6}$ and 17.

\begin{tabular}{lcccccc}
\hline & \multicolumn{3}{c}{16} & \multicolumn{3}{c}{17} \\
Method & $\mathrm{Si}-\mathrm{O}(\AA)$ & $\mathrm{P}^{\cdots} \mathrm{O}(\AA)$ & $\mathrm{Si}{ }^{\cdots} \mathrm{P}(\AA)$ & $\mathrm{Si}-\mathrm{F}(\AA)$ & $\mathrm{P}^{\cdots} \mathrm{F}(\AA)$ & $\mathrm{Si}{ }^{\cdots} \mathrm{P}(\AA)$ \\
\hline X-ray molecule 1 & $1.645^{a}$ & 3.207 & 4.851 & $1.600^{a}$ & 3.251 & 4.851 \\
X-ray molecule 2 & $1.645^{a}$ & 3.540 & 5.185 & $1.600^{a}$ & 3.585 & 5.185 \\
B3LYP/6-311++G(2df,2pd) & 1.641 & 3.532 & 5.168 & 1.613 & 3.631 & 5.244
\end{tabular}

${ }^{a}$ Distance was fixed at the indicated value in the X-ray refinement.

The phosphorus-oxygen and phosphorus-fluorine non-bonded contact distances differ by more than $0.3 \AA$ in the experimental structures, with the calculated values more closely resembling the longer distance in molecule 2. We have previously observed that the B3LYP functional overestimates cyclophane non-bonded contact distances, ${ }^{18}$ but this is a relatively small effect in comparison to the seemingly very large effect of crystal packing forces on these molecules. The sum of the van der Waals radii of phosphorus and oxygen is $3.35 \AA$ and that of phosphorus and fluorine is $3.35-3.45 \AA$, ${ }^{14}$ so that in molecule 1 the two atoms are perhaps slightly compressed, while in molecule 2 and the calculated geometries they are barely touching.

The through-space coupling of the fluorine and phosphorus atoms in $\mathbf{1 7}$ is calculated to be $104 \mathrm{~Hz}$ at the B3LYP/6-311++G(2df,2pd) level, in excellent agreement with the experimental $J_{\mathrm{FP}}=112$ Hz. The experimental value is one of the largest reported through-space ${ }^{19} \mathrm{~F}^{31} \mathrm{P}$ coupling constants. Three larger examples are known: $184 \mathrm{~Hz},{ }^{19} 144 \mathrm{~Hz}$, and $130 \mathrm{~Hz} ;{ }^{20,21}$ however, all three are found in 1,8-disubstituted naphthalene derivatives where the $\mathrm{F}$ and $\mathrm{P}$ atoms are separated by only four bonds. In the present case, the two atoms are separated by nine bonds, so that there is really no possibility of an ordinary through-bond coupling mechanism. 
The in,in-cyclophanes described herein are large enough to contain a non-hydrogen atom in their central cavities, yet small enough that the internal atoms must interact with both ends of the cyclophane. The silver complex $\mathbf{1 2}$ is an unusual transition metal complex, given that the silver ion is entirely enclosed by a hydrophobic macrocycle, but it does not display any extraordinary properties. It is likely that other metals can be encapsulated by bisphosphine 11, but thus far we have been unable to form even the corresponding gold complex. The purely organic atom encapsulations, compounds $\mathbf{1 6}$ are 17, are extremely rare examples of cyclophanes with innon-hydrogen atoms. The pendant internal hydroxyl group and fluorine atom are pressed against the inwardly directed, opposing phosphine lone pair, and the $\mathrm{F}^{\cdots} \mathrm{P}$ interaction is close enough to result in a very large through-space coupling constant. It is unknown whether even larger in-atoms can be enclosed in the same way. 


\section{Experimental}

\subsection{General}

Tris[2-(chloromethyl)phenyl]phosphine ${ }^{11}$ and tris[2-(methoxymethyl)phenyl]silane ${ }^{15}$ were prepared as described previously. All other solvents and reagents were commercial, reagent grade materials, and they were used without further purification. ${ }^{1} \mathrm{H}$ NMR spectra were recorded at $300 \mathrm{MHz}$ on a Bruker AVANCE 300 spectrometer, at $400 \mathrm{MHz}$ on a Varian Unity INOVA 400 spectrometer, and at $500 \mathrm{MHz}$ on a Bruker AVANCE 500 spectrometer. ${ }^{13} \mathrm{C}$ NMR spectra were recorded at $75 \mathrm{MHz}, 101 \mathrm{MHz}$, and $126 \mathrm{MHz}$, respectively, on the same instruments. ${ }^{31} \mathrm{P}$ NMR spectra were recorded on Varian Unity INOVA spectrometer at $161 \mathrm{MHz}$. Samples were dissolved in $\mathrm{CDCl}_{3}$. MALDI-TOF mass spectra were recorded on a Bruker Autoflex III spectrometer, and high-resolution ESI-TOF mass spectra were recorded on an Agilent 6220 spectrometer.

\subsection{Data for compounds}

4.2.1. Tris[2-(mercaptomethyl)phenyl]phosphine (10). A solution of tris[2-(chloromethyl)phenyl]phosphine $(\mathbf{9}, 408 \mathrm{mg}, 1.00 \mathrm{mmol})$ and thiourea $(228 \mathrm{mg}, 3.00 \mathrm{mmol})$ in EtOH $(10 \mathrm{~mL})$ was heated at reflux overnight. After cooling, the solvent was removed, and $\mathrm{KOH}(385 \mathrm{mg})$ in water $(15 \mathrm{~mL})$ was added to the remaining white salt under argon. This solution was heated at reflux for $5 \mathrm{~h}$, cooled to room temperature, acidified with $1 \mathrm{~N} \mathrm{HCl}$, and extracted three times with $\mathrm{CH}_{2} \mathrm{Cl}_{2}$. The combined extracts were dried over $\mathrm{Na}_{2} \mathrm{SO}_{4}$ and concentrated in vacuo to give the desired trithiol 1 (386 mg, $0.964 \mathrm{mmol}, 96 \%) . \quad{ }^{1} \mathrm{H} \mathrm{NMR}\left(\mathrm{CDCl}_{3}\right) \delta 2.01$ (td, $\left.J=8 \mathrm{~Hz}, 2 \mathrm{~Hz}, 3 \mathrm{H}\right)$, $3.92(\mathrm{dd}, J=8 \mathrm{~Hz}, 1 \mathrm{~Hz}, 6 \mathrm{H}), 6.83$ (ddd, $J=7.5 \mathrm{~Hz}, 4.5 \mathrm{~Hz}, 1 \mathrm{~Hz}, 3 \mathrm{H}), 7.16$ (ddd, $J=7.5 \mathrm{~Hz}, 7.5$ $\mathrm{Hz}, 1 \mathrm{~Hz}, 3 \mathrm{H}), 7.36$ (ddd, $J=7.5 \mathrm{~Hz}, 7.5 \mathrm{~Hz}, 1 \mathrm{~Hz}, 3 \mathrm{H}), 7.42(\mathrm{~m}, 3 \mathrm{H}) ;{ }^{13} \mathrm{C} \mathrm{NMR}\left(\mathrm{CDCl}_{3}\right) \delta 28.2$ $\left(\mathrm{d}, J_{\mathrm{PC}}=25 \mathrm{~Hz}\right), 127.8,129.9\left(\mathrm{~d}, J_{\mathrm{PC}}=6 \mathrm{~Hz}\right), 130.2,133.5\left(\mathrm{~d}, J_{\mathrm{PC}}=10 \mathrm{~Hz}\right), 134.6,146.1\left(\mathrm{~d}, J_{\mathrm{PC}}=\right.$ 
$25 \mathrm{~Hz}$ ) (7 of 7 expected resonances); HRMS (ESI) $401.0616(\mathrm{M}+\mathrm{H})$, calcd for $\mathrm{C}_{21} \mathrm{H}_{22} \mathrm{PS}_{3}$ 401.0621 .

4.2.2. in,in-Bis(phosphine) 11. Tris[2-(chloromethyl)phenyl]phosphine (9, $383 \mathrm{mg}, 0.939 \mathrm{mmol})$ and tris[2-(mercaptomethyl)phenyl]phosphine (10, $376 \mathrm{mg}, 0.939 \mathrm{mmol})$ were mixed in 2:1 benzene-ethanol $(900 \mathrm{~mL})$, and the solution was heated to reflux under argon. An argon-saturated solution of $\mathrm{KOH}(253 \mathrm{mg}, 4.5 \mathrm{mmol})$ in ethanol $(50 \mathrm{~mL})$ was added slowly over $3 \mathrm{~h}$. After $16 \mathrm{~h}$, the solution was cooled, and the solvent was evaporated under reduced pressure to leave a white solid. The solid was extracted twice with chloroform, and the combined extracts were concentrated to yield a light yellow liquid. This material was chromatographed on silica gel (solvent, 1:1 hexanes-benzene) to give compound $\mathbf{1 1}$ as a white solid (144 mg, $0.206 \mathrm{mmol}, 22 \%$ ). A portion of this material was purified further by preparative silica gel TLC (solvent, 1:1 hexanes-benzene), and the resulting solid was recrystallized from acetone- $\mathrm{CH}_{2} \mathrm{Cl}_{2}$ to give single crystals of 11 suitable for X-ray analysis. ${ }^{1} \mathrm{H}$ NMR $\left(\mathrm{CDCl}_{3}\right) \delta 3.4-4.8(\mathrm{br}, 12 \mathrm{H}), 6.78(\mathrm{dd}, J=7.5$ Hz, $1 \mathrm{~Hz}, 6 \mathrm{H}), 7.14$ (ddd, J=7.5 Hz, 7.5 Hz, $1 \mathrm{~Hz}, 6 \mathrm{H}), 7.28$ (ddd, J= 7.5 Hz, 7.5 Hz, $1 \mathrm{~Hz}, 6 \mathrm{H})$, $7.37(\mathrm{~m}, 6 \mathrm{H}) ;{ }^{13} \mathrm{C} \mathrm{NMR}\left(\mathrm{CDCl}_{3}\right) \delta 38.0$ (m; AA' component of AA'XX' system, where the X's are ${ }^{31}$ P nuclei), 127.9, 129.4, 130.5, 134.7, 136.2 (m; as above), 142.0 (m; as above) (7 of 7 expected resonances); HRMS (ESI) $699.1522(\mathrm{M}+\mathrm{H})$, calcd for $\mathrm{C}_{42} \mathrm{H}_{37} \mathrm{P}_{2} \mathrm{~S}_{3} 699.1532$.

4.2.3. $\mathbf{A g}(\mathbf{I}) \cdot 11$ Acetate (12). Silver acetate $(1.0 \mathrm{mg}, 6.0 \mu \mathrm{mol})$ was added to a solution of compound $11(2.0 \mathrm{mg}, 2.9 \mu \mathrm{mol})$ in $\mathrm{CDCl}_{3}(1 \mathrm{~mL})$. The solution was stirred at room temperature for $16 \mathrm{~h}$. Residual solid was filtered away, and the filtrate was mixed with tert-butyl methyl ether. Slow concentration of the solution gave compound $\mathbf{1 2}$ as crystals ( $c a .2 \mathrm{mg}$ ) suitable for X-ray analysis. ${ }^{1} \mathrm{H} \mathrm{NMR}\left(\mathrm{CDCl}_{3}\right) \delta 2.23(\mathrm{~s}, 3 \mathrm{H}), 4.17(\mathrm{~d}, J=10.5 \mathrm{~Hz}, 6 \mathrm{H}), 4.24(\mathrm{~d}, J=10.5 \mathrm{~Hz}, 6 \mathrm{H})$, $6.75(\mathrm{~m}, 6 \mathrm{H}), 7.33(\mathrm{~m}, 6 \mathrm{H}), 7.56(\mathrm{~m}, 12 \mathrm{H}) ;{ }^{13} \mathrm{C} \mathrm{NMR}\left(\mathrm{CDCl}_{3}\right) \delta 29.7,39.2$ (m; AA' component of AA'XX' system, where the X's are ${ }^{31} \mathrm{P}$ nuclei), 129.7, 132.7, 132.8, 134.4 (6 of 9 expected resonances; the two quaternary carbons of $\mathbf{1 2}$ and the acetate carbonyl are invisible; in addition, 
the resonances at $\delta 129.7,132.8$, and 134.4 are clearly broadened due to unresolved long-range coupling to $\mathrm{P}$ and $\mathrm{Ag}) ;{ }^{31} \mathrm{P} \mathrm{NMR}\left(\mathrm{CDCl}_{3}\right) \delta-28.9\left(\mathrm{dd}, J_{\mathrm{AgP}}=556 \mathrm{~Hz}\left[{ }^{109} \mathrm{Ag}\right.\right.$ coupling $\left.]\right), J_{\mathrm{AgP}}=482$ $\left.\mathrm{Hz}\left[{ }^{107} \mathrm{Ag}\right]\right) ; \mathrm{MS}\left(\right.$ MALDI-TOF) $\mathrm{m} / z 805\left(\mathbf{1 1}{ }^{\cdot 107} \mathrm{Ag}^{+}, 82\right), 807\left(\mathbf{1 1} \cdot{ }^{109} \mathrm{Ag}^{+}, 100\right)$.

4.2.4. Tris[2-(chloromethyl)phenyl]silanol (14). Boron trichloride (1 M in heptane, $100 \mathrm{~mL}$, $100 \mathrm{mmol}$ ) was added to tris[2-(methoxymethyl)phenyl]silane $(\mathbf{1 3}, 1.76 \mathrm{~g}, 4.49 \mathrm{mmol})$ in a round bottom flask under argon. The mixture was stirred at room temperature for $2 \mathrm{~h}$ and then heated at reflux for $3 \mathrm{~h}$. After cooling to room temperature, $\mathrm{CHCl}_{3}$ and water were added. The organic layer was separated, and the aqueous phase was extracted again with $\mathrm{CHCl}_{3}$. The combined extracts were dried over $\mathrm{Na}_{2} \mathrm{SO}_{4}$ and concentrated to dryness. The resulting white solid was chromatographed on silica gel (solvent, $3: 1 \mathrm{CHCl}_{3}$-hexanes) to give compound $\mathbf{1 4}$ as a white solid (616 mg, $1.46 \mathrm{mmol}, 32 \%) . \quad{ }^{1} \mathrm{H} \mathrm{NMR}\left(\mathrm{CDCl}_{3}\right) \delta 3.90$ (br, $\left.1 \mathrm{H}\right), 4.72(\mathrm{~s}, 6 \mathrm{H}), 7.27$ (m, $\left.6 \mathrm{H}\right), 7.50$ $(\mathrm{m}, 3 \mathrm{H}), 7.56(\mathrm{~d}, J=7.5 \mathrm{~Hz}, 3 \mathrm{H}) ;{ }^{13} \mathrm{C} \mathrm{NMR}\left(\mathrm{CDCl}_{3}\right) \delta 47.1,128.2,131.0,131.5,134.4,137.0$, 143.9 (7 of 7 expected resonances); HRMS (ESI) $443.0179\left(\mathrm{M}+\mathrm{Na}\right.$ ), calcd for $\mathrm{C}_{21} \mathrm{H}_{19} \mathrm{Cl}_{3} \mathrm{NaOSi}$ 443.0168 .

4.2.5. Tris[2-(chloromethyl)phenyl]fluorosilane (15). Tris[2-(chloromethyl)phenyl]silanol (14, $1.05 \mathrm{~g}, 2.49 \mathrm{mmol})$ was dissolved in $\mathrm{CH}_{2} \mathrm{Cl}_{2}(50 \mathrm{~mL}), \mathrm{BF}_{3}$ etherate $(3 \mathrm{~mL})$ was added dropwise, and the solution was stirred at room temperature overnight. The resulting material was chromatographed on silica gel (solvent, 3:1 $\mathrm{CHCl}_{3}$-hexanes) to give compound $\mathbf{1 5}$ as a white solid (585 mg, $1.38 \mathrm{mmol}, 55 \%) . \quad{ }^{1} \mathrm{H} \mathrm{NMR}\left(\mathrm{CDCl}_{3}\right) \delta 4.64(\mathrm{~s}, 6 \mathrm{H}), 7.34(\mathrm{~m}, 6 \mathrm{H}), 7.57$ (ddd, $J=7 \mathrm{~Hz}$, $7 \mathrm{~Hz}, 2 \mathrm{~Hz}, 3 \mathrm{H}), 7.63(\mathrm{~d}, J=7.5 \mathrm{~Hz}, 3 \mathrm{H}) ;{ }^{13} \mathrm{C} \mathrm{NMR}\left(\mathrm{CDCl}_{3}\right) \delta 46.2\left(\mathrm{~d}, J_{\mathrm{FC}}=3 \mathrm{~Hz}\right), 128.1,130.7$, $131.3\left(\mathrm{~d}, J_{\mathrm{FC}}=16 \mathrm{~Hz}\right), 132.3,136.9\left(\mathrm{~d}, J_{\mathrm{FC}}=4 \mathrm{~Hz}\right), 144.1(7 \mathrm{of} 7$ expected resonances $) ; \mathrm{HRMS}$ (ESI) $445.0123(\mathrm{M}+\mathrm{Na})$, calcd for $\mathrm{C}_{21} \mathrm{H}_{18} \mathrm{Cl}_{3} \mathrm{FNaSi} 445.0125$.

4.2.6. in-Hydroxysilane-in-phosphine 16. Tris[2-(chloromethyl)phenyl]hydroxysilane (14, 166 $\mathrm{mg}, 0.375 \mathrm{mmol})$ and tris[2-(mercaptomethyl)phenyl]phosphine $(\mathbf{1 0}, 150 \mathrm{mg}, 0.374 \mathrm{mmol})$ were 
mixed in 2:1 benzene-ethanol $(315 \mathrm{~mL})$, and the resulting solution was heated to reflux under argon. An argon-saturated solution of $\mathrm{KOH}(90 \mathrm{mg})$ in ethanol (40 mL) was added slowly over 3 h. After $26 \mathrm{~h}$, the solution was cooled, and the solvent was removed under reduced pressure. The residue was extracted twice with hot $\mathrm{CHCl}_{3}$, and the combined extracts were concentrated and chromatographed on a silica gel column (solvent, 3:2 hexanes-benzene). Concentrations of the appropriate fractions gave pure cyclophane $16(38 \mathrm{mg}, 0.053 \mathrm{mmol}, 14 \%) .{ }^{1} \mathrm{H} \mathrm{NMR}\left(\mathrm{CDCl}_{3}\right) \delta$ 3.90 (br, 3 H), 4.14 (br, 6 H), 4.59 (br, 3 H), 6.50 (d, J = 4 Hz, $1 \mathrm{H}), 6.75$ (ddd, J = 7.5 Hz, 4 Hz, 1 $\mathrm{Hz}, 3 \mathrm{H}), 7.98(\mathrm{dt}, J=7 \mathrm{~Hz}, 1 \mathrm{~Hz}, 3 \mathrm{H}), 7.13(\mathrm{~m}, 6 \mathrm{H}), 7.32(\mathrm{dd}, J=7.5 \mathrm{~Hz}, 1 \mathrm{~Hz}, 3 \mathrm{H}), 7.38$ (m, 12 $\mathrm{H}) ;{ }^{13} \mathrm{C} \mathrm{NMR}\left(\mathrm{CDCl}_{3}\right) \delta 37.8\left(\mathrm{~d}, J_{\mathrm{PC}}=26 \mathrm{~Hz}\right), 40.3,126.4,127.7,129.4,130.2,130.4,130.7(\mathrm{~d}$, $\left.J_{\mathrm{PC}}=5 \mathrm{~Hz}\right), 134.3\left(\mathrm{~d}, J_{\mathrm{PC}}=11 \mathrm{~Hz}\right), 134.7,135.7,136.7,141.6\left(\mathrm{~d}, J_{\mathrm{PC}}=28 \mathrm{~Hz}\right), 143.8(14 \mathrm{of} 14$ expected resonances). HRMS (ESI) $713.1588(\mathrm{M}+\mathrm{H})$, calcd for $\mathrm{C}_{42} \mathrm{H}_{38} \mathrm{OPS}_{3} \mathrm{Si} 713.1592$.

\subsubsection{Mixture of in-Fluorosilane-in-phosphine 17 and in-Hydroxysilane-in-phosphine 16.}

Tris[2-(chloromethyl)phenyl]fluorosilane $(\mathbf{1 5}, 170 \mathrm{mg}, 0.401 \mathrm{mmol})$ and tris[2-(mercaptomethyl)phenyl]phosphine (10,160 mg, $0.399 \mathrm{mmol})$ were mixed in 2:1 benzene-ethanol (360 $\mathrm{mL})$, and the resulting solution was heated to reflux under argon. An argon-saturated solution of $\mathrm{KOH}$ (74 mg) in ethanol $(50 \mathrm{~mL})$ was added slowly over $5 \mathrm{~h}$. After $16 \mathrm{~h}$, the solution was cooled, and the solvent was removed under reduced pressure to leave a yellow solid. This solid was extracted twice with $\mathrm{CHCl}_{3}$, and the combined extracts were concentrated to give a light yellow liquid. This material was chromatographed on silica gel (solvent, 1:1 hexanes-benzene), and the fractions containing compounds 16 and 17 were combined and further purified by preparative silica gel TLC (solvent, 1:1 hexanes-benzene) to give the inseparable 16/17 mixture as a white solid (3 $\mathrm{mg}$, $0.004 \mathrm{mmol}, 1 \%$ ). Evaporation of a $\mathrm{CHCl}_{3}$ solution gave crystals suitable for $\mathrm{X}$-ray analysis. NMR analysis showed that the sample was predominantly compound 16 (NMR integration gives ca. 4:1 16:17) and the reported ${ }^{1} \mathrm{H}$ and ${ }^{13} \mathrm{C}$ NMR spectra are those of $\mathbf{1 6}$. Subspectra for 17 were partly observed in the ${ }^{1} \mathrm{H}$ NMR spectrum and invisible in the ${ }^{13} \mathrm{C}$ NMR spectrum. ${ }^{1} \mathrm{H}$ NMR $\left(\mathrm{CDCl}_{3}\right) \delta 3.89(\mathrm{br}, 3 \mathrm{H}), 4.13(\mathrm{br}, 6 \mathrm{H}), 4.56(\mathrm{br}, 3 \mathrm{H}), 6.48(\mathrm{~d}, J=4 \mathrm{~Hz}, 1 \mathrm{H}), 6.73(\mathrm{ddd}, J=7.5 \mathrm{~Hz}$, 


\begin{abstract}
$4 \mathrm{~Hz}, 1 \mathrm{~Hz}, 3 \mathrm{H}), 7.96(\mathrm{~d}, J=7 \mathrm{~Hz}, 3 \mathrm{H}), 7.12(\mathrm{~m}, 6 \mathrm{H}), 7.30(\mathrm{dd}, J=7.5 \mathrm{~Hz}, 1 \mathrm{~Hz}, 3 \mathrm{H}), 7.38(\mathrm{~m}$, $12 \mathrm{H}) ;{ }^{13} \mathrm{C} \mathrm{NMR}\left(\mathrm{CDCl}_{3}\right) \delta 38.0\left(\mathrm{~d}, J_{\mathrm{PC}}=26 \mathrm{~Hz}\right), 40.6,126.6,128.0,129.7,130.5,130.6,130.9(\mathrm{~d}$, $\left.J_{\mathrm{PC}}=5 \mathrm{~Hz}\right), 134.6\left(\mathrm{~d}, J_{\mathrm{PC}}=11 \mathrm{~Hz}\right), 134.9,135.9,137.0,141.9\left(\mathrm{~d}, J_{\mathrm{PC}}=28 \mathrm{~Hz}\right), 144.0(14$ of 14 expected resonances). ${ }^{31} \mathrm{P}$ NMR and mass spectral analysis showed distinct spectra for compounds 16 and 17. For 16: ${ }^{31} \mathrm{P}$ NMR $\left(\mathrm{CDCl}_{3}\right) \delta$-37.5; HRMS (ESI) $713.1615(\mathrm{M}+\mathrm{H})$, calcd for $\mathrm{C}_{42} \mathrm{H}_{38} \mathrm{OPS}_{3} \mathrm{Si} 713.1592$. For 17: ${ }^{31} \mathrm{P} \mathrm{NMR}\left(\mathrm{CDCl}_{3}\right) \delta-40.3\left(\mathrm{~d}, J_{\mathrm{FP}}=112 \mathrm{~Hz}\right)$; HRMS (ESI) $715.1629(\mathrm{M}+\mathrm{H})$, calcd for $\mathrm{C}_{42} \mathrm{H}_{37} \mathrm{FPS}_{3} \mathrm{Si} 715.1548$.
\end{abstract}

\title{
4.3. Computational Methodology
}

Quantum calculations were performed using Gaussian $09,{ }^{22}$ and its built-in default parameters for integral accuracy, and wave function and gradient convergence were employed. The B3LYP and B3PW91 functionals ${ }^{23-25}$ with the 6-311++G(2df,2pd) basis set ${ }^{26}$ were employed for calculations in this study. Full geometry optimizations were performed at the specified level of theory, and NMR spectral data were calculated at the same level as the optimizations by using the GIAO method [keywords NMR=(SPINSPIN,MIXED)].

\section{Acknowledgment}

This work was supported by National Science Foundation Grant CHE-1265507, which is gratefully acknowledged. The X-ray diffractometer used in this work was purchased with funds from National Science Foundation Grant MRI-1228232.

\section{Supplementary Data}

(1) ${ }^{1} \mathrm{H}$ and ${ }^{13} \mathrm{C}$ NMR spectra of compounds $10,11,12,14,15,16$, and 16/17; ${ }^{31} \mathrm{P}$ NMR spectra of compounds 12 and 16/17; atomic coordinates of the HDFT-calculated structures of compounds 16 
and 17. (2) Crystallographic data (excluding structure factors) for the structures in this paper have been deposited with the Cambridge Crystallographic Data Centre as supplementary publication numbers CCDC 1503001-1503003. Copies of the data can be obtained, free of charge, on application to CCDC, 12 Union Road, Cambridge, CB2 1EZ, UK [fax: +44(0)-1223-336033 or e-mail: deposit@ccdc.cam.ac.uk].

\section{References and Notes}

1. Zong, J.; Mague, J. T.; Kraml, C. M.; Pascal, R. A., Jr. Org. Lett. 2013, 15, 2179-2181.

2. Zong, J.; Mague, J. T.; Pascal, R. A., Jr. J. Am. Chem. Soc. 2013, 135, 13235-13237.

3. Zong, J., Mague, J. T.; Welch, E. C.; Eckert, I. M. K.; Pascal, R. A., Jr. Tetrahedron 2013, 69, 10316-10321.

4. Pascal, R. A., Jr.; Zong, J.; Dougherty, K. J.; Geng, X.; Mague, J. T. Tetrahedron 2014, 70, 7518-7526.

5. $\quad$ Alder, R. W.; East, S. P. Chem. Rev. 1996, 96, 2097-2111.

6. Bauer, I.; Habicher, W. D. Collect. Czech. Chem. Commun. 2004, 69, 1195-1230.

7. Bauer I.; Rademacher O.; Gruner M.; Habicher W. D. Chem. Eur. J. 2000, 6, 3043-3051.

8. Bauer I.; Fröhlich R.; Ziganshina A.; Prosvirkin A.; Gruner M.; Kazakova E. Kh.; Habicher, W. D. Chem. Eur. J. 2002, 8, 5622-5629.

9. (a) Groom, C. R.; Bruno, I. J.; Lightfoot, M. P.; Ward, S. C. Acta Crystallogr., Sect. B 2016, B72, 171-179. (b) Allen, F. H. Acta Crystallogr., Sect. B 2002, B58, 380-388.

10. Skopek, K.; Barbasiewicz, M.; Hampel, F.; Gladysz, J. A. Inorg. Chem. 2008, 47, 3474-3476.

11. Letsinger, R. L.; Nazy, J. R.; Hussey, A. S. J. Org. Chem. 1958, 23, 1806-1807.

12. Van der Sluis, P.; Spek, A. L. Acta Crystallogr., Sect. A 1990, A46, 194-201.

13. (a) Shannon, R. D. Acta Crystallogr., Sect. A 1976, A32, 751-767. (b) Huheey, J. E. Inorganic Chemistry; Harper \& Row: New York, 1983; p. $73-76$ (Table 3.4). 
14. (a) Bondi, A. J. Phys. Chem. 1964, 68, 441-451. (b) Huheey, J. E. Inorganic Chemistry; Harper \& Row: New York, 1983; p. 258-259 (Table 6.1).

15. Takeuchi, Y.; Yamamoto, H.; Tanaka, K.; Ogawa, K.; Harada, J.; Iwamoto, T.; Yuge, H. Tetrahedron 1998, 54, 9811-9822.

16. These reactions are unpublished, but a very similar problem is discussed in Dell, S. J.; Ho, D. M.; Pascal, R. A., Jr. J. Org. Chem. 1999, 64, 5626-5633.

17. Dracinsky, M.; Jansa, P.; Bour, P. Chem. Eur. J. 2012, 18, 981-986.

18. Pascal, R. A., Jr. J. Phys. Chem. A 2001, 105, 9040-9048.

19. Mallory, F. B.; Mallory, C. W. Encyclopedia of Nuclear Magnetic Resonance; Grant, D. M., Harris, R. K., Eds.; J. Wiley \& Sons: Chichester, 1996; Vol. 3, pp 1491-1501.

20. Mallory, F. B.; Mallory, C. W.; Butler, K. E.; Lewis, M. B.; Xia, A. Q.; Luzik, E. D., Jr.; Fredenburgh, L. E.; Ramanjulu, M. M.; Van, Q. N.; Francl, M. M.; Freed, D. A.; Wray, C. C.; Hann, C.; Nerz-Stormes, M.; Carroll, P. J.; Chirlian, L. E. J. Am. Chem. Soc. 2000, 122, 4108-4116.

21. Hierso, J.-C. Chem. Rev. 2014, 114, 4838-4867.

22. Gaussian 09, Revision A.02, Frisch, M. J.; Trucks, G. W.; Schlegel, H. B.; Scuseria, G. E.; Robb, M. A.; Cheeseman, J. R.; Scalmani, G.; Barone, V.; Mennucci, B.; Petersson, G. A.; Nakatsuji, H.; Caricato, M.; Li, X.; Hratchian, H. P.; Izmaylov, A. F.; Bloino, J.; Zheng, G.; Sonnenberg, J. L.; Hada, M.; Ehara, M.; Toyota, K.; Fukuda, R.; Hasegawa, J.; Ishida, M.; Nakajima, T.; Honda, Y.; Kitao, O.; Nakai, H.; Vreven, T.; Montgomery, Jr., J. A.; Peralta, J. E.; Ogliaro, F.; Bearpark, M.; Heyd, J. J.; Brothers, E.; Kudin, K. N.; Staroverov, V. N.; Kobayashi, R.; Normand, J.; Raghavachari, K.; Rendell, A.; Burant, J. C.; Iyengar, S. S.; Tomasi, J.; Cossi, M.; Rega, N.; Millam, J. M.; Klene, M.; Knox, J. E.; Cross, J. B.; Bakken, V.; Adamo, C.; Jaramillo, J.; Gomperts, R.; Stratmann, R. E.; Yazyev, O.; Austin, A. J.; Cammi, R.; Pomelli, C.; Ochterski, J. W.; Martin, R. L.; Morokuma, K.; Zakrzewski, V. G.; Voth, G. A.; Salvador, P.; Dannenberg, J. J.; Dapprich, S.; Daniels, A. D.; Farkas, Ö.; Foresman, J. B.; Ortiz, J. V.; Cioslowski, J.; Fox, D. J. Gaussian, Inc., Wallingford CT, 2009. 
23. Becke, A. D. J. Chem. Phys. 1993, 98, 5648-5652.

24. (a) Lee, C.; Yang, W.; Parr, R. G. Phys. Rev. B 1988, 37, 785-789. (b) Miehlich, B.; Savin, A.; Stoll, H.; Preuss, H. Chem. Phys. Lett. 1989, 157, 200-206.

25. Perdew, J. P.; Wang, Y. Phys. Rev. B 1992, 45, 13244-13249.

26. Hehre, W. J.; Radom, L.; Schleyer, P. v. R.; Pople, J. A. Ab Initio Molecular Orbital Theory; John Wiley \& Sons: New York, 1986; pp 63-100. 


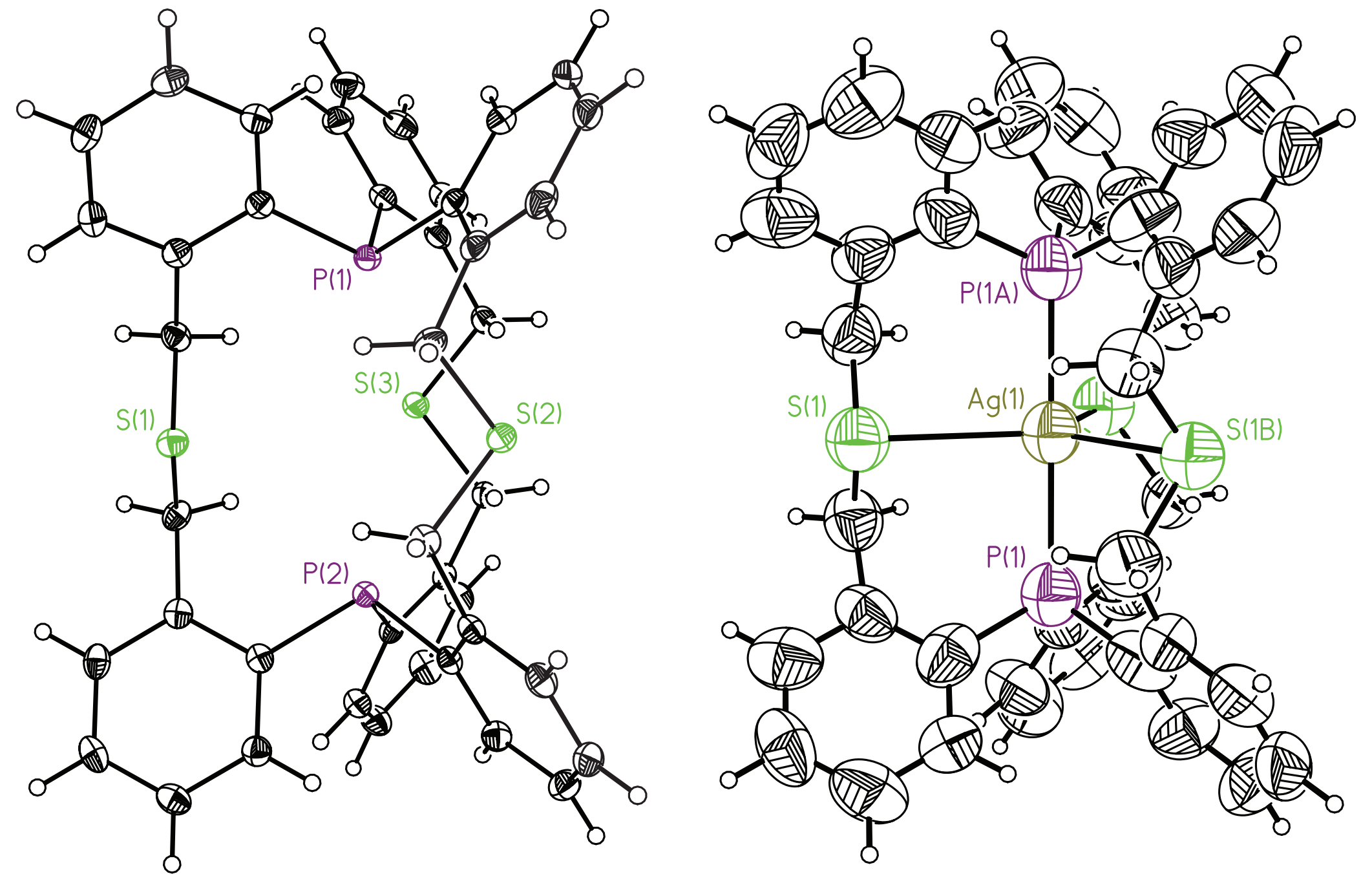




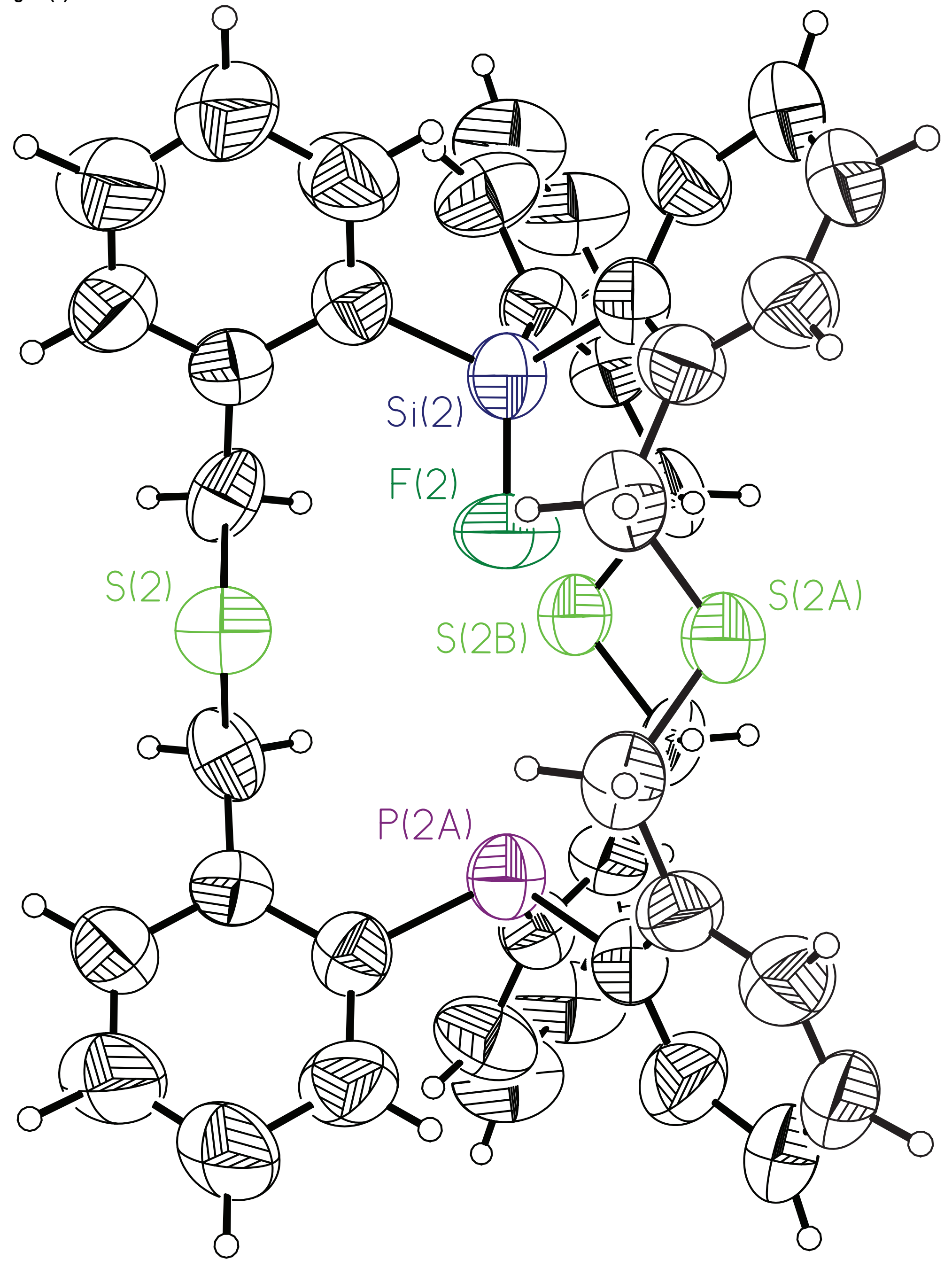




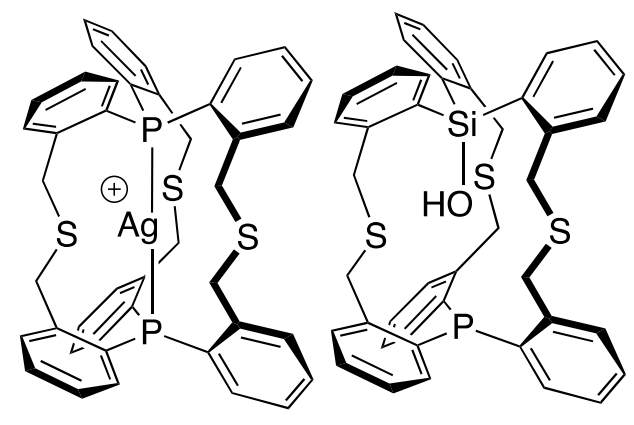

